\title{
Escala de Amor: Elaboração de Itens e Estudos Psicométricos Iniciais
}

\author{
Love Scale: Items Development and Initial Psychometric Studies
}

\author{
Susana König Luz ${ }^{1}$, Ana Paula Porto Noronha ${ }^{2}$ e João Lucas Dias-Viana ${ }^{3}$
}

\begin{abstract}
Resumo
Este estudo teve como objetivo construir e reunir evidências de validade com base no conteúdo e na estrutura interna para uma escala de avaliação do amor romântico com fundamentação teórica na teoria triangular do amor. A justificativa consiste na tentativa tentar ultrapassar problemas psicométricos encontrados no instrumento elaborado pelo autor original e em estudos posteriores. Para a validação de conteúdo (Estudo 1), participaram 10 pesquisadores brasileiros, doutores em Psicologia. Para avaliação da compreensão dos itens pela população-alvo, foi realizado um estudo piloto com 10 universitários brasileiros. Para investigação da estrutura interna e estimativa da precisão da escala (Estudo 2), participaram 527 estudantes universitários brasileiros, com idades variando de 18 a 69 anos $(M=23.24 ; D P=6.30)$, que estavam em algum tipo de relacionamento amoroso. Os participantes responderam ao questionário de identificação sociodemográfica e à Escala de Amor (E-AMOR). As análises indicaram um modelo hierárquico de segunda-ordem, sendo o amor o fator geral, e os fatores intimidade, paixão, decisão/compromisso, como fatores específicos de primeira-ordem. A escala também apresentou boas estimativas de precisão. Os resultados permitem considerar a E-AMOR um instrumento adequado para mensuração do amor e seus três componentes.
\end{abstract}

Palavras-chave: amor, compromisso, casais; construção de teste, relações amorosas

\begin{abstract}
This study aimed to develop and gather validity evidence based on content and internal structure for a romantic love rating scale with a theoretical framework in the triangular theory of love. The justification consists of the attempt to overcome the psychometric inconsistencies found in the instrument developed by the original author and in subsequent studies. For content validation, 10 researchers with PhDs in Psychology and 10 undergraduate students participated in the pilot study sample. To investigate the internal structure and scale reliability, 527 Brazilian undergraduate students, with ages ranging from 18 to 69 years, $(M=23.24$; $S D=6.30$ ), who were in a romantic relationship participated in the study. The participants responded to identification questionnaire and the Love Scale (E-AMOR). The analyses indicated a second-order model, love as a high-order factor, and intimacy, passion, and decision /commitment, as specific first-order factors. The scale also showed good estimates of internal consistency. The results point to E-AMOR being an adequate instrument for measuring love and its three components.
\end{abstract}

Keywords: couples, commitment, love, loving relationships, test construction

\footnotetext{
${ }^{1}$ Psicóloga pela Universidade de Passo Fundo. Mestre em Psicologia pela Universidade do Rio dos Sinos. Doutora em Psicologia pela Universidade São Francisco. Professora da Universidade de Passo Fundo, Brasil. ORCID: 0000-0001-9508-1699. E-mail: susana.konig@hotmail.com

${ }^{2}$ Psicóloga, Mestre em Psicologia Escolar e Doutora em Psicologia Ciência e Profissão pela Pontifícia Universidade Católica de Campinas. Professora Associada do Programa de Pós-Graduação Stricto Sensu em Psicologia da Universidade São Francisco, Brasil. É bolsista produtividade em pesquisa 1A do CNPq. ORCID: 0000-0001-6821-0299 E-mail: ana.noronha@usf.edu.br

${ }^{3}$ Psicólogo pela Universidade Estadual do Ceará. Mestre e Doutorando em Psicologia, com ênfase em Avaliação Psicológica pela Universidade São Francisco. ORCID: 0000-0002-7626-3937. E-mail: jolucasviana@gmail.com
}

Revista Iberoamericana de Diagnóstico y Evaluación - e Avaliação Psicológica. RIDEP · No61 · Vol.4 · 205-217 · 2021

ISSN: $1135-3848$ print /2183-6051online 


\section{Introdução}

É possível medir o amor? Mensurar o amor é uma tarefa difícil, uma vez que se trata de um construto multidimensional, composto por aspectos cognitivos, comportamentais e emocionais, e que pode assumir formas de expressão distintas (Peterson \& Seligman, 2004). O amor é uma experiência afetiva humana básica, presente nas mais diversas culturas, que inspira e motiva filósofos e pesquisadores a identificar os motivos e mecanismos que fazem com que as pessoas optem por se relacionar e por manter vínculos afetivos com outros (Lucas, Csikszentmihalyi, \& Nakamura, 2019). É compreendido como um sentimento profundo e relevante, no qual está presente uma forte afeição por outra pessoa, nascida dos laços de consanguinidade ou de relações sociais (Rubin, 1970). Os estudos têm evidenciado que o amor está associado ao bem-estar (Hudson, Lucas, \& Donnellan, 2019) e indicadores de saúde mental (Mirsu-Paun \& Oliver, 2017).

Segundo estudo de Fehr e Russel (1991), o amor assume três formas prototípicas. A primeira diz respeito ao amor direcionado às pessoas que são a nossa primeira fonte de cuidado, afeto e proteção, um exemplo típico é o amor de uma criança para com os seus pais. A segunda forma prototípica consiste no amor sentido pelos pais em relação aos filhos (e.g. amor materno e paterno), os quais fornecem carinho, cuidado, assistem e prestam o suporte necessário à prole. É considerada a forma mais prototípica de amor. Os pais são capazes de fazer sacrifícios, deixando suas necessidades de lado e priorizando as dos filhos. A terceira forma diz respeito ao "amor romântico", objeto de estudo desta pesquisa, envolve a paixão, a volição de proximidade, a atração sexual e o desejo de envolvimento físico e emocional com alguém considerado especial e que desencadeia um sentimento de felicidade. No que diz respeito ao amor romântico, Sternberg é um dos principais teóricos acerca da temática. Por esta razão, este autor foi escolhido para subsidiar a construção da escala de amor a que se propõe este estudo.

De acordo com a teoria triangular do amor (Sternberg, 1986, 1988), o amor romântico seria constituído por três componentes, metaforicamente comparados aos vértices de um triângulo: intimidade, paixão e decisão/ compromisso. Intimidade refere-se ao sentimento de proximidade, conexão e vínculo em relações amorosas. É o componente que envolve afetos positivos e entusiásticos acerca da pessoa amada, como o desejo de promover o seu bem-estar, ter suporte em momentos de necessidade, doação e apoio emocional ao cônjuge, compartilhamento de si e dos seus bens. A paixão, por sua vez, é o componente vinculado à atração física, ao desejo sexual, ao romance e à satisfação por estar envolvido em um relacionamento amoroso, importante componente para a relação conjugal. Embora as necessidades sexuais predominem, outros fatores como carinho, afiliação e autoestima contribuem para a experiência de apaixonar-se. Decisão/compromisso é composto por dois aspectos distintos, quais sejam, decisão de manter uma relação amorosa com alguém e, a intenção de preservar o relacionamento a longo prazo.

Embasado em sua teoria, Sternberg (1997) elaborou a Triangular Scale of Love (Escala Triangular do Amor de Sternberg - ETAS). O instrumento possui 72 itens, distribuídos igualmente entre os três fatores, com chave de resposta em escala tipo Likert, variando de 1(de forma alguma) a 9 (extremamente). Os coeficientes de consistência do instrumento foram estimados em $\alpha=.97$ para a escala geral, $\alpha=.91$ para o fator intimidade, $\alpha=.94$ para paixão e $\alpha=.90$ para comprometimento. A correlação entre os fatores foi de $r_{\text {paixão-intimidade }}=.71, \quad r_{\text {paixão- }}$ comprometimento $=.74$ e $r_{\text {comprometimento-intimidade }}=.73$, portanto, altos coeficientes. Em que pese o fato, a elevada correlação entre eles indica alta comunalidade, ou seja, as variáveis estão linearmente correlacionadas (Cassepp-Borges \& Pasquali, 2014).

No cenário internacional, estudos realizados com o instrumento indicaram melhores índices de ajuste para uma estrutura unifatorial (Acker \& Davis, 1992; Aron \& Westbay, 1996; Carreño \& Serrano, 1995; Chojnacki \& Walsh, 1990; Hendrick \& Hendrick, 1989; Whitley, 1993). No entanto, há na literatura pesquisas que utilizaram a ETAS e chegaram à solução de três fatores (Haack \& Falcke, 2014; Sumter, Valkenburg, \& Peter, 2013), embora problemas tenham sido 
identificados na tentativa de replicabilidade do modelo (Batinic et al., 2016; Draganović \& Hasanagic, 2015), o que pode sugerir problemas na construção da escala ou na expectativa teórica sobre o construto.

No Brasil, a primeira adaptação da ETAS foi publicada por Hernandez (1999), em um estudo com 98 participantes. Utilizando-se de análise fatorial confirmatória por componentes principais e rotação varimax, o pesquisador encontrou evidências de validade de estrutura interna para a escala e, além disso, forte consistência interna, expressa por alfas superiores a .90 para cada uma das três subescalas. Embora a estrutura da escala tenha sido identificada com nitidez, os níveis de correlação entre as subescalas foram elevados e, também, foi constatado um número expressivo de itens que não carregaram nos fatores prescritos pela teoria.

Posteriormente, Cassepp-Borges e Teodoro (2007) realizaram novo estudo de adaptação e validação da ETAS (Sternberg, 1997), com busca de evidência de validade de conteúdo, por meio da aplicação em 361 estudantes universitários, e análise fatorial exploratória, com rotação promax. A análise fatorial indicou que sete itens apresentaram o mesmo comportamento relatado por Hernandez (1999), carregando em outros fatores não designados teoricamente. Aliados a isso, o instrumento apresenta itens complexos no que diz respeito à clareza de linguagem, contendo itens que avaliam mais de um comportamento.

Gouveia, Fonseca, Cavalcanti, Diniz e Dória (2009) pesquisaram uma versão de 45 itens, intitulada Escala Triangular do Amor - Versão Reduzida. Os resultados indicaram uma solução fatorial de três componentes, portanto replicando o modelo teórico proposto por Sternberg, que explicaram $67.7 \%$ da variância total, com rotação varimax. Os alfas para cada componente foram: compromisso $(\alpha=.88)$, paixão $(\alpha=.87)$ e intimidade $(\alpha=.86)$.

Uma nova versão da Escala Triangular do Amor de Sternberg - Reduzida foi testada por Andrade, Garcia e Cassepp-Borges (2013). Os autores partiram das escalas anteriores disponíveis em português (Cassepp-Borges \& Teodoro, 2007, Gouveia et al., 2009) e do original em inglês, de Sternberg. Dividiram a amostra de 1.530 pessoas em duas, a fim de realizar análise fatorial exploratória e confirmatória. Como resultados, foi confirmada a estrutura de três fatores da medida, com estimativa de precisão superior a .80 . Posteriormente, Cassepp-Borges e Pasquali (2014) verificaram as propriedades psicométricas da Escala Triangular do Amor de Sternberg Reduzida (20 itens). Os resultados indicaram que a versão reduzida possui boa precisão, $\operatorname{com} \alpha=.94$, e estrutura unifatorial.

Diante do exposto, evidencia-se que estudos nacionais e internacionais realizados com a ETAS apresentam divergência de soluções fatoriais, e que medidas existentes apresentam limitações quanto à construção de itens, e análises fatoriais com rotações ortogonais ao invés de oblíquas utilizadas quando há relações entre os fatores. Face às dificuldades mencionadas, propõe-se a construção de um novo instrumento, a Escala de Amor (E-AMOR), com o intuito de corrigir tais dificuldades e de chegar ao modelo que avalie os componentes de intimidade, paixão e decisão/compromisso, segundo a teoria proposta por Sternberg (1986). Serão apresentados os estudos de construção de itens e busca de evidências de validade com base no conteúdo e na estrutura interna do instrumento, além do cálculo das estimativas de precisão. Ademais, considerando a divergência de soluções fatoriais encontradas e alta correlação entres os fatores, uma estrutura bi-factor e um modelo fatorial de segunda-ordem serão testados, possibilidades que ainda não foram exploradas em estudos anteriores. Assim, para além da análise da estrutura interna do instrumento, o estudo possibilitará uma melhor compreensão da teoria de amor proposta por Sternberg (1986).

\section{Método}

\section{Estudo 1: Construção e evidências de validade de conteúdo}

A construção dos itens da Escala de Amor (EAMOR) se deu de maneira teórica, tendo como referência os pressupostos da teoria triangular do amor (Sternberg, 1986) que prevê a organização do construto em três dimensões, a saber: paixão, intimidade e decisão/compromisso. Foram elaborados pela primeira autora 50 itens, dos quais 15 para a dimensão paixão, 20 para a intimidade e 15 para decisão/compromisso. Em seguida, os 
itens foram revisados pela segunda autora em relação à adequação de conteúdo, palavras usadas e análise semântica.

\section{Participantes}

O estudo contou com diferentes amostras para cada uma das etapas realizadas. Para a análise de juízes foram selecionados 10 psicólogos, doutores em psicologia, professores universitários, com expertise em avaliação psicológica e pesquisadores. A taxa de retorno foi de $60 \%$, ficando a amostra com seis juízes do sexo masculino, com idades entre 34 e 60 anos $(M=43.17 ; D P=1.50)$ e tempo de doutorado entre 5 e 18 anos $(M=9.83 ; D P=5.11)$. Para o estudo piloto, participaram 10 estudantes de psicologia que cursavam o oitavo semestre diurno, divididos em dois grupos. O grupo 1 foi composto por quatro mulheres e um homem, com idades entre 20 e 45 anos $(M=29.42 ; D P=11.21)$. O grupo 2 foi composto por cinco mulheres, com idades entre 20 e 24 anos $(M=21.60 ; D P=1.12)$. Considerou-se como critério de inclusão da amostra, estar em relacionamento amoroso e ter idade igual ou superior a 18 anos.

\section{Instrumentos}

Além de solicitadas informações como idade e tempo de doutorado, foi elaborado um formulário contendo instruções para a tarefa, uma breve explicação sobre os componentes da teoria triangular do amor de Sternberg (1986), construto sob o qual a escala está amparada, e os itens. Para a amostra do estudo piloto foi utilizado o mesmo formulário encaminhado aos juízes, todavia sem a introdução sobre os componentes da teoria triangular do amor, pois o objetivo era testar a clareza e a capacidade de compreensão dos itens.

\section{Procedimento}

Após a aprovação do projeto pelo Comitê de Ética em Pesquisa da Universidade São Francisco (USF), sob o número CAAE: 53659916.6.0000.5514, os juízes foram contatados via e-mail para serem informados sobre os objetivos da pesquisa. Quando do aceite, foram enviados a eles o Termo de Consentimento Livre e Esclarecido (TCLE), e a planilha para avaliação dos itens. A tarefa dos juízes consistia em identificar a qual componente da teoria triangular do amor cada um dos itens estava associado. Em relação ao estudo piloto, os participantes assinaram ao TCLE e, em seguida, a pesquisadora entregou o protocolo para avaliação da E-AMOR. Após a leitura de cada item, era perguntado a eles se os itens estavam compreensíveis. O tempo de duração do estudo piloto foi de 40 minutos.

\section{Análise de Dados}

As sugestões advindas dos juízes foram comparadas com as respostas esperadas, nomeadas de gabarito. Depois de avaliar as concordâncias entre as respostas, os pesquisadores providenciaram as alterações necessárias. Foram mantidos itens que apresentassem concordância interavaliadores igual ou superior a $80 \%$. A etapa seguinte consistiu em analisar os comentários e sugestões advindas dos participantes do estudo piloto.

\section{Resultados do Estudo 1}

Inicialmente, as respostas dos juízes foram comparadas quanto às categorias atribuídas pelas duas primeiras autoras, quais sejam: paixão, intimidade, decisão/compromisso e não se aplica. Dos 50 itens analisados, constatou-se que 1 item apresentava conteúdo muito similar a outro, motivo pelo qual foi excluído, totalizando 49. Como é possível observar no Quadro 1, dos 49 itens, 20 apresentaram baixo índice de concordância interavaliadores (inferiores a 80\%), o que resultou na remoção desses itens para a etapa seguinte. Desse modo, foram mantidos os 29 itens que apresentaram índices de concordância igual ou superior a $80 \%$.

Com a finalidade de realizar a análise semântica dos itens, foi feito um estudo piloto para verificar a compreensão e a clareza dos itens, bem como das instruções da escala. Os itens foram compreendidos pelos participantes, não havendo dúvidas quanto à compreensão, razão pela qual a etapa não gerou alterações no instrumento. Ao final da etapa de validação de conteúdo, restaram 29 itens para o estudo de estrutura interna da E-AMOR. 
Quadro 1. Concordância entre as respostas da análise de juízes

\begin{tabular}{|c|c|c|}
\hline $\begin{array}{l}\text { Número } \\
\text { do item }\end{array}$ & Item original & $\begin{array}{c}\text { Concordância } \\
\text { em \% }\end{array}$ \\
\hline 1 & Estou satisfeita(o) com a relação com meu/minha parceiro(a) & 33.33 \\
\hline 2 & Tenho um forte compromisso com meu/minha parceiro(a) & 10.00 \\
\hline 3 & Importo-me com todas as coisas do meu/minha parceiro(a) & 16.66 \\
\hline 4 & Percebo quando meu/minha parceiro(a) está chateado(a) & 10.00 \\
\hline 5 & Tenho muito desejo pelo meu/minha parceiro(a) & 10.00 \\
\hline 6 & Quando sei que irei magoar meu/minha parceiro(a), tenho cuidado para falar o que penso & 83.33 \\
\hline 7 & Gosto das fantasias sexuais que tenho com meu/minha parceiro(a) & 67.66 \\
\hline 8 & Aceito meu/minha parceiro(a) do jeito que ele(a) é & 67,66 \\
\hline 9 & Sinto-me responsável pelo bem-estar de meu/minha parceiro(a) & 5.00 \\
\hline 10 & Abriria mão de ascensão profissional, se isso interferisse positivamente em minha relação com meu/minha parceiro(a) & 83.33 \\
\hline 11 & Sou muito satisfeito(a) sexualmente com meu/minha parceiro(a) & 10.00 \\
\hline 12 & Valorizo muito a opinião de meu/minha parceiro(a) & 83.33 \\
\hline 13 & Sinto muita atração física pelo meu/minha parceiro(a) & 10.00 \\
\hline 14 & Tenho uma relação sólida com meu/minha parceiro(a) & 5.00 \\
\hline 15 & Divido as minhas coisas com meu/minha parceiro(a) & 67.66 \\
\hline 16 & Acredito no apoio de meu/minha parceiro(a) em relação a mim & 83.33 \\
\hline 17 & Gosto de mandar mensagens para meu/minha parceiro(a) ao longo do dia & 16.66 \\
\hline 18 & Sou fiel ao meu/minha parceiro(a) & 10.00 \\
\hline 19 & Me arrumo pensando em chamar a atenção do meu/minha parceiro(a) & 83.33 \\
\hline 20 & Deixaria de fazer um projeto pessoal para agradar meu/minha parceiro(a) & 83.33 \\
\hline 21 & Tenho vontade de ter relações sexuais com meu/minha parceiro(a) várias vezes ao dia & 10.00 \\
\hline 22 & O amor pelo meu/minha parceiro(a) me completa & 16.66 \\
\hline 23 & Quando estou apaixonado(a), fico empolgado(a) & 83.33 \\
\hline 24 & Meu/minha parceiro(a) sempre pergunta minha opinião sobre os assuntos de seu interesse & 83.33 \\
\hline 25 & Prefiro estar com meu/minha parceiro(a) do que em outro lugar & 33.33 \\
\hline 26 & Respeito a opinião de meu/minha parceiro(a) mesmo que eu não concorde & 67.66 \\
\hline 27 & Eu e meu/minha parceiro(a) nos respeitamos e evitamos discutir em público & 33.33 \\
\hline 28 & Meu relacionamento com meu/minha parceiro(a) é duradouro & 67.66 \\
\hline 29 & Consigo perceber quando meu/minha parceiro(a) está com problemas & 10.00 \\
\hline 30 & Me apaixonei pelo meu/minha parceiro(a) assim que o(a) vi & 33.33 \\
\hline 31 & Penso em meu/minha parceiro(a) várias horas por dia & 16.66 \\
\hline 32 & Quando assisto cenas de um filme romântico, penso em meu/minha parceiro(a) & 10.00 \\
\hline 33 & Acredito no amor de meu/minha parceiro(a) por mim & 67.33 \\
\hline 34 & Na relação com meu/minha parceiro(a), existe algo mágico & 10.00 \\
\hline 35 & Divido meus planos de vida com meu/minha parceiro(a) & 83.33 \\
\hline 36 & Sou muito apaixonada(o) pelo meu/minha parceiro(a) & 33.33 \\
\hline 37 & Tenho certeza de meu amor pelo meu/minha parceiro(a) & 10.00 \\
\hline 38 & Não me importaria em compartilhar meus bens com meu/minha parceiro(a) & 67.66 \\
\hline 39 & A relação com meu/minha parceiro(a) foi uma das melhores decisões da minha vida & 10.00 \\
\hline 40 & Espero admirar meu parceiro(a) por toda vida & 83.33 \\
\hline 41 & Apoiaria meu/minha parceiro(a) mesmo não concordando com a escolha feita por ele(a) & 16.66 \\
\hline 42 & Empenho-me para que meu/minha parceiro(a) se sinta seguro no relacionamento & 16.66 \\
\hline 43 & Esforço-me para manter meu relacionamento & 83.33 \\
\hline 44 & Escolho não ter relações sexuais com outras pessoas & 83.33 \\
\hline 45 & Compartilho com meu/minha parceiro(a) minhas intimidades & 10.00 \\
\hline 46 & Gostaria de manter a relação com meu/minha parceiro(a) por muito tempo & 83.33 \\
\hline 47 & Ajudo meu/minha parceiro(a) a cuidar de sua saúde & 10.00 \\
\hline 48 & Em momentos de necessidade meu/minha parceiro(a) pode contar com meu apoio & 83.33 \\
\hline 49 & Peço a opinião do meu/minha parceiro(a) quando sinto necessidade & 83.33 \\
\hline
\end{tabular}

\section{Estudo 2: Evidências de Validade com base na estrutura interna}

\section{Participantes}

Participaram desta etapa da pesquisa 527 estudantes universitários de uma instituição de ensino superior do interior do Rio Grande do Sul, Brasil, com idades variando de 18 a 69 anos, $(M=23.24 ; D P=6.30)$, sendo $269(51 \%)$ do sexo feminino e 258 (49\%) do sexo masculino. Considerou-se como critério de inclusão da amostra, estar em relacionamento amoroso. Quanto ao estado civil, 67.90\% (n=358) dos participantes afirmaram estar namorando; $15.40 \%$
( $n=81)$ estavam em união estável; $13.70 \%(n=72)$ eram casados; $3 \%$ ( $n=16)$ eram noivos. O tempo de relacionamento variou de 1 a 45 anos, sendo a mediana igual a 3 anos $(M=3.53$ anos; $D P=4.25)$. Do total de participantes, $90.70 \% \quad(n=478)$ não possuem filhos.

\section{Instrumentos}

\section{Questionário de Identificação Sociodemográfica}

Instrumento desenvolvido pelos autores do estudo com o objetivo de caracterização dos participantes. As perguntas investigavam variáveis como: sexo, idade, tipo de relacionamento amoroso e tempo de relacionamento. 


\section{Escala de Amor (E-AMOR)}

Instrumento de autorrelato composto por 29 itens, respondido em escala Likert, variando de 1 (Nada/Muito pouco) a 5 (Muito/ Em excesso). Os itens da escala foram construídos de acordo com a teoria proposta por Sternberg (1986), na qual o amor seria composto por três componentes: intimidade, paixão e decisão/compromisso. O primeiro componente, intimidade, possui itens que demonstram o envolvimento de sentimentos positivos e entusiásticos sobre o(a) parceiro(a) e a relação ("Sinto-me responsável pelo bem-estar de meu/minha parceiro" e "Valorizo muito a opinião de meu/minha parceiro"). O segundo componente, paixão, consiste nos itens vinculados à atração física, ao desejo sexual, ao romance e à satisfação por estar envolvido em um relacionamento amoroso ("Sinto muita atração física pelo meu/minha parceiro(a)" e "Gosto das fantasias sexuais que tenho com meu/minha parceiro(a)"). O terceiro componente, decisão/ compromisso, contém itens que possibilitam entender dois aspectos distintos: a decisão de amar alguém e o compromisso em manter esse relacionamento ("Tenho um forte compromisso com meu/minha parceiro(a)" e "Tenho uma relação sólida com meu/minha parceiro(a)"). A versão do instrumento utilizada nesta etapa da pesquisa foi desenvolvida no Estudo 1.

\section{Procedimentos Éticos}

Os participantes manifestaram sua anuência em participar da pesquisa mediante assinatura do TCLE. As aplicações foram coletivas, nas respectivas salas de aula dos estudantes, com tempo médio de aplicação de 30 minutos.

\section{Análise de Dados}

Para análise se a matriz de dados era passível de fatoração, calculou-se o teste de esfericidade de Bartlett e teste de Kaiser-Meyer-Olkin (KMO). Com o intuito de investigar as soluções fatoriais da E-AMOR utilizou-se Análise Paralela, o Minimum Average Partial (MAP), o Bayesian Information Criterion (BIC) e o método de Hull (Damásio, 2012). Em seguida, realizou-se análise fatorial confirmatória (AFC), em que os itens foram atribuídos aos fatores conforme etapa de avaliação dos juízes; com matriz de correlação policórica e estimador Mean and Variance Adjusted Weighted
Least Square (WLSMV). A AFC foi realizada no software Mplus. Os seguintes índices de ajuste do modelo aos dados foram utilizados: Chi Square/degrees of freedom ( $\chi 2 / \mathrm{df} ;<2)$, Comparative Fit Index (CFI>.90), Tucker Lewis Index (TLI>.90) e Root Mean Square Error of Approximation no intervalo de confiança de $90 \%$ (RMSEA IC 90\%<.10) (Marôco, 2010). Calculouse o alfa de Cronbach e confiabilidade composta para estimativa da precisão dos escores do instrumento. Em seguida, com o objetivo de testar um modelo bi-factor para investigar a existência de um fator geral, especificado como amor, e de três componentes específicos (intimidade, paixão e decisão/ compromisso) que funcionariam como fatores ortogonais ao fator geral. Além disso, foi testado um modelo hierárquico de segunda-ordem, em que o amor seria um fator geral de segundaordem e intimidade, paixão e decisão/ compromisso fatores de primeira-ordem. As análises fatoriais bi-factor e de segunda-ordem também foram realizadas no software Mplus.

\section{Resultados do Estudo 2}

A análise da estrutura interna da Escala de Amor foi realizada com o objetivo de verificar se os três fatores teóricos propostos por Sternberg (paixão, intimidade e decisão/compromisso) se confirmavam empiricamente. Inicialmente, para verificar se a matriz de dados era passível de fatoração, calculouse o índice Kaiser-Meyer-Olkin (KMO) e o Teste de Esfericidade de Bartlett, que apresentaram valores de .94 e $p<.001$, respectivamente, indicando a adequação da matriz de dados para realização de Análise Fatorial.

Dada a complexidade de mensuração do amor e a divergência de soluções fatoriais encontradas em estudos anteriores, utilizou-se diversos métodos de retenção fatorial para investigação da estrutura interna da E-AMOR. Utilizando-se o intervalo de confiança de 95\%, o método de Hull e a Análise Paralela sugeriram uma solução unifatorial, o Minimum Average Partial (MAP) recomendou dois fatores, e o BIC a retenção de 3 fatores.

Considerando as recomendações de retenção fatorial e a divergência na quantidade de fatores nas medidas de amor existentes que utilizaram a teoria de triangular do amor de Sternberg (1986), optou-se por seguir duas linhas de investigação: 
Quadro 2. Análise fatorial confirmatória para a estrutura unifatorial

\begin{tabular}{|c|c|c|c|}
\hline $\begin{array}{l}\mathrm{N}^{\circ} \text { atual } \\
\text { do item }\end{array}$ & $\begin{array}{l}\mathrm{N}^{\circ} \text { original } \\
\text { do item }\end{array}$ & Item & $\begin{array}{l}\text { Carga } \\
\text { Fatorial }\end{array}$ \\
\hline 1 & 2 & Tenho um forte compromisso com meu/minha parceiro(a) & .74 \\
\hline 2 & 4 & Percebo quando meu/minha parceiro(a) está chateado(a) & .59 \\
\hline 3 & 5 & Tenho muito desejo pelo meu/minha parceiro(a) & .66 \\
\hline 4 & 6 & Quando sei que irei magoar meu/minha parceiro(a), tenho cuidado para falar o que penso & .33 \\
\hline 5 & 10 & $\begin{array}{l}\text { Abriria mão de ascensão profissional, se isso interferisse positivamente em minha relação com } \\
\mathrm{meu} / \text { minha parceiro(a) }\end{array}$ & .52 \\
\hline 6 & 11 & Sou muito satisfeito(a) sexualmente com meu/minha parceiro(a) & .66 \\
\hline 7 & 12 & Valorizo muito a opinião de meu/minha parceiro(a) & .69 \\
\hline 8 & 13 & Sinto muita atração física pelo meu/minha parceiro(a) & .73 \\
\hline 9 & 16 & Acredito no apoio de meu/minha parceiro(a) em relação a mim & .77 \\
\hline 10 & 18 & Sou fiel ao meu/minha parceiro(a) & .70 \\
\hline 11 & 19 & Me arrumo pensando em chamar a atenção do meu/minha parceiro(a) & .50 \\
\hline 12 & 20 & Deixaria de fazer um projeto pessoal para agradar meu/minha parceiro(a) & .50 \\
\hline 13 & 21 & Tenho vontade de ter relações sexuais com meu/minha parceiro(a) várias vezes ao dia & .36 \\
\hline 14 & 23 & Quando estou apaixonado(a), fico empolgado(a) & .50 \\
\hline 15 & 24 & Meu/minha parceiro(a) sempre pergunta minha opinião sobre os assuntos de seu interesse & .58 \\
\hline 16 & 29 & Consigo perceber quando meu/minha parceiro(a) está com problemas & .52 \\
\hline 17 & 32 & Quando assisto cenas de um filme romântico, penso em meu/minha parceiro(a) & .63 \\
\hline 18 & 34 & Na relação com meu/minha parceiro(a), existe algo mágico & .66 \\
\hline 19 & 35 & Divido meus planos de vida com meu/minha parceiro(a) & .80 \\
\hline 20 & 37 & Tenho certeza de meu amor pelo meu/minha parceiro(a) & .84 \\
\hline 21 & 39 & A relação com meu/minha parceiro(a) foi uma das melhores decisões da minha vida & .80 \\
\hline 22 & 40 & Espero admirar meu/minha parceiro(a) por toda vida & .86 \\
\hline 23 & 43 & Me esforço para manter meu relacionamento & .77 \\
\hline 24 & 44 & Escolho não ter relações sexuais com outras pessoas & .63 \\
\hline 25 & 45 & Compartilho com meu/minha parceiro(a) minhas intimidades & .80 \\
\hline 26 & 46 & Gostaria de manter a relação com meu/minha parceiro(a) por muito tempo & .87 \\
\hline 27 & 47 & Ajudo meu/minha parceiro(a) a cuidar de sua saúde & .71 \\
\hline 28 & 48 & Em momentos de necessidade meu/minha parceiro(a) pode contar com meu apoio & .77 \\
\hline 29 & 49 & Peço a opinião do meu/minha parceiro(a) quando sinto necessidade & .78 \\
\hline \multicolumn{3}{|c|}{ Coeficiente alfa Cronbach } & .95 \\
\hline \multicolumn{3}{|c|}{ Coeficiente ômega de McDonald } & .95 \\
\hline
\end{tabular}

solução unifatorial e a de três fatores. Desse modo, realizou-se análise fatorial confirmatória com os 29 itens, e estrutura unifatorial. Foi considerado o valor igual ou superior a $.30 \mathrm{de}$ carga fatorial para a retenção de itens. Conforme pode ser observado no Quadro 2, observou-se que as cargas fatoriais, variaram de .33 a $.87 . \mathrm{O}$ modelo apresentou $57 \%$ de variância explicada e coeficientes de consistência interna foram alfa de Cronbach igual a .94 de e ômega de McDonald de 95. Os índices de ajuste observados, foram $\chi^{2}=2337.34 ; \quad \mathrm{df}=378 ; \quad \chi^{2} / \mathrm{gl}=6.18 ; \quad$ RMSEA IC $90 \%=.10-.11 ; \mathrm{CFI}=.87$ e TLI=.86.

Em seguida, realizou-se análise fatorial confirmatória seguindo os pressupostos da teoria triangular do amor (Sternberg, 1986), com o objetivo de investigar a existência dos três fatores: intimidade, paixão, decisão/compromisso. Os itens foram inseridos no modelo de acordo com as dimensões para as quais foram criados. Conforme pode ser visto no Quadro 3, as cargas fatoriais dos itens foram consideradas adequadas, variando de .34 a .88, com coeficientes de consistência interna considerados adequados para cada um dos fatores, variando de .82 a .93. Quanto aos índices de ajuste do modelo, obteve-se $\chi^{2}=1672.54 ; \quad \mathrm{df}=347$; $\chi^{2} / \mathrm{df}=4.82$; RMSEA IC $90 \%=.08-.09 ; \mathrm{CFI}=.92$; $\mathrm{TLI}=.91$. Observou-se alta correlação entre os fatores, com $r$ intimidade x paixão=.79; $r$ intimidade $\mathrm{x}$ decisão $=.95 ; r$ paixão x decião/compromisso .77 .

No modelo bi-factor, foi especificado um fator geral, nomeado Amor, que seria responsável por explicar a maior parte da comunalidade dos itens. Intimidade, Paixão e Decisão foram especificados como fatores ortogonais ao fator geral, que explicariam a variância dos itens para além do fator geral. Observa-se a partir da Quadro 4 , que todos os itens apresentaram cargas fatorias significativas no fator geral, variando de .34 a .88 . Quanto aos fatores específicos, dos 29 itens analisados, percebeu-se que oito itens apresentaram cargas fatoriais significativas acima de .30: dois itens em Intimidade, quatro em Paixão e dois em Decisão. Os dados de ajuste do modelo foram RMSEA $=.067$; RMSEA IC $90 \%=.063-.071 ; \chi^{2}=1167.11 ; \mathrm{df}=348 ; \chi^{2} / \mathrm{df}=3.35$; $\mathrm{CFI}=.953 ; \mathrm{TLI}=.945$.

Um modelo hierárquico com um fator latente de segunda ordem pode ser admissível quando os fatores possuem altas correlações entre eles, ou/e 
Quadro 3. Análise fatorial confirmatória para estrutura composta por três fatores

\begin{tabular}{|c|c|c|c|c|}
\hline \multicolumn{2}{|c|}{ Item } & \multirow{2}{*}{$\begin{array}{c}\text { Intimidade } \\
61\end{array}$} & \multirow[t]{2}{*}{ Paixão } & \multirow[t]{2}{*}{$\begin{array}{c}\text { Decisão/ } \\
\text { Compromisso }\end{array}$} \\
\hline 2 & Percebo quando meu/minha parceiro(a) está chateado(a) & & & \\
\hline 4 & Quando sei que irei magoar meu/minha parceiro(a), tenho cuidado para falar o que penso & .34 & & \\
\hline 7 & Valorizo muito a opinião de meu/minha parceiro (a) & .71 & & \\
\hline 9 & Acredito no apoio de meu/minha parceiro (a) em relação a mim & .80 & & \\
\hline 15 & $\mathrm{Meu} /$ minha parceiro(a) sempre pergunta minha opinião sobre os assuntos de seu interesse & .60 & & \\
\hline 16 & Consigo perceber quando meu/minha parceiro(a) está com problemas & .53 & & \\
\hline 19 & Divido meus planos de vida com meu/minha parceiro(a) & .82 & & \\
\hline 25 & Compartilho com meu/minha parceiro(a) minhas intimidades & .82 & & \\
\hline 27 & Ajudo meu/minha parceiro(a) a cuidar de sua saúde & .73 & & \\
\hline 28 & Em momentos de necessidade meu/minha parceiro (a) pode contar com meu apoio & .79 & & \\
\hline 29 & Peço a opinião do meu/minha parceiro(a) quando sinto necessidade & .80 & & \\
\hline 3 & Tenho muito desejo pelo meu/minha parceiro(a) & & .75 & \\
\hline 6 & Sou muito satisfeito(a) sexualmente com meu/minha parceiro(a) & & .75 & \\
\hline 8 & Sinto muita atração física pelo meu/minha parceiro(a) & & .84 & \\
\hline 11 & Me arrumo pensando em chamar a atenção do meu/minha parceiro(a) & & .56 & \\
\hline 13 & Tenho vontade de ter relações sexuais com meu/minha parceiro(a) várias vezes ao dia & & .43 & \\
\hline 14 & Quando estou apaixonado(a), fico empolgado(a) & & .57 & \\
\hline 17 & Quando assisto cenas de um filme romântico, penso em meu/minha parceiro(a) & & .72 & \\
\hline 18 & Na relação com meu/minha parceiro(a), existe algo mágico & & .76 & \\
\hline 1 & Tenho um forte compromisso com meu/minha parceiro(a) & & & .75 \\
\hline 5 & Abriria mão de ascensão profissional se isso interferisse positivamente em minha relação com meu/minha parceiro(a) & & & .54 \\
\hline 10 & Sou fiel ao meu/minha parceiro(a) & & & .72 \\
\hline 12 & Deixaria de fazer um projeto pessoal para agradar meu/minha parceiro(a) & & & .51 \\
\hline 20 & Tenho certeza de meu amor pelo meu/minha parceiro(a) & & & .81 \\
\hline 21 & A relação com meu/minha parceiro(a) foi uma das melhores decisões da minha vida & & & .86 \\
\hline 22 & Espero admirar meu/minha parceiro(a) por toda vida & & & .88 \\
\hline 23 & Me esforço para manter meu relacionamento & & & .79 \\
\hline 24 & Escolho não ter relações sexuais com outras pessoas & & & .65 \\
\hline 26 & Gostaria de manter a relação com meu/minha parceiro(a) por muito tempo & & & .87 \\
\hline & Coeficiente alfa de Cronbach & .88 & .82 & .90 \\
\hline & Coeficiente ômega de McDonald & .91 & .86 & .93 \\
\hline
\end{tabular}

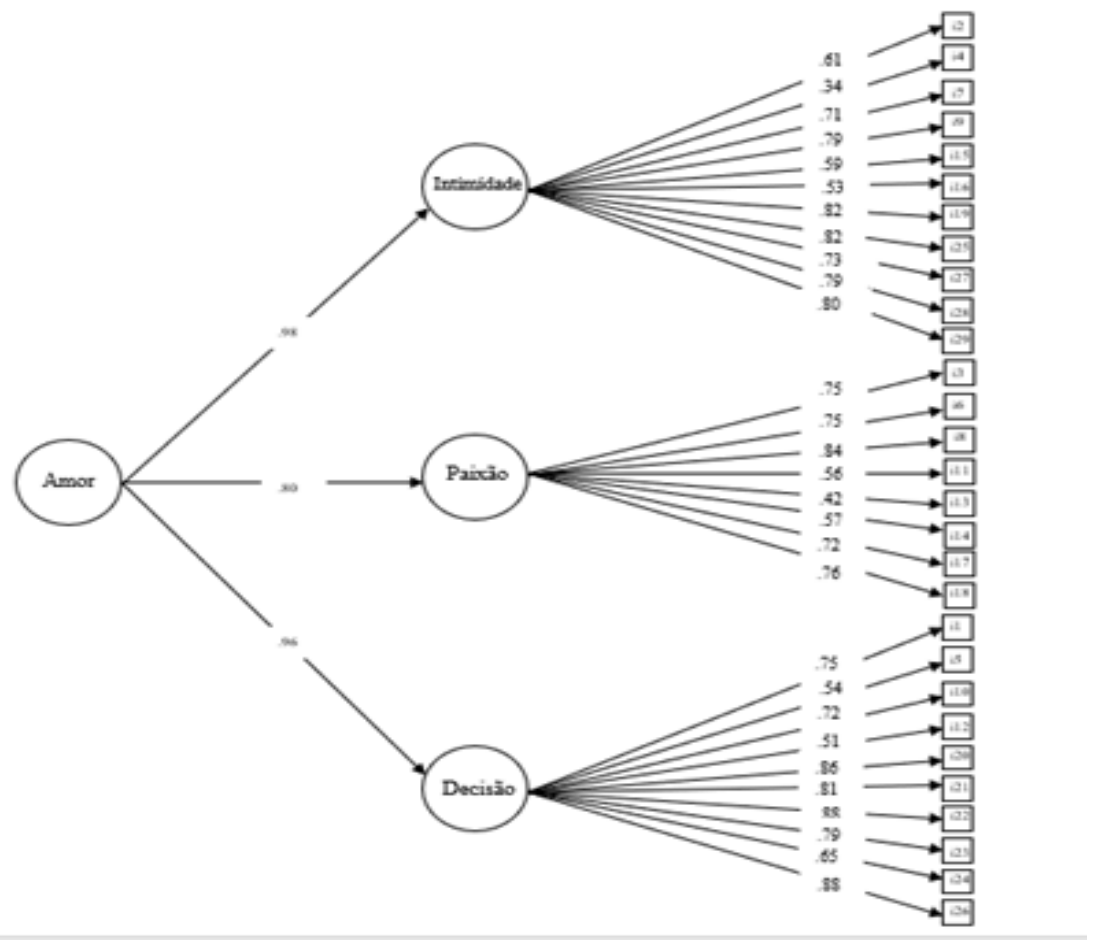

Figura 1. Estrutura Fatorial do modelo de segunda-ordem da E-Amor

quando existe um construto de ordem superior que pode explicar os fatores de ordem inferior. Assim, um modelo de segunda-ordem foi testado. Amor foi considerado como o construto latente de segunda-ordem e Intimidade, Paixão e Decisão/
Compromisso como os fatores específicos de primeira-ordem (ver Figura 1). A estrutura fatorial de segunda-ordem apresentou RMSEA=.085; RMSEA IC $90 \%=.081-.089 ; \chi^{2}=1804.91 ; \mathrm{df}=374$; $\chi^{2} / \mathrm{df}=4.82 ; \mathrm{CFI}=.918 ; \mathrm{TLI}=.911$. Os coeficientes 
estruturais do Amor para Intimidade $(\gamma=.98 ; p<.001), \quad$ Paixão $\quad(\gamma=.80 ; p<.001) \quad$ e Decisão/ Compromisso $(\gamma=.96 ; p<.001)$ foram altos.

\section{Discussão}

Este trabalho teve como objetivo apresentar o processo de construção e de evidências de validade com base no conteúdo na estrutura interna de uma escala de amor. A mensuração do amor romântico caracteriza-se como uma tarefa difícil, dada a complexidade do construto e a limitação dos instrumentos existentes. Nesse sentido, foi elaborada a Escala de Amor (EAMOR), que tem por objetivo a mensuração do vínculo afetivo de pessoas que estão em relacionamento romântico. O embasamento teórico utilizado para a elaboração do instrumento foi a teoria triangular do amor (Sternberg, 1986), em que o amor teria como componentes a Paixão, Intimidade, Decisão/Compromisso.

No que diz respeito à estrutura interna do instrumento, as recomendações de soluções fatoriais foram divergentes, com recomendações unifatoriais e com três fatores, divergências também observadas na literatura científica em instrumentos que se propõem a medir o amor e embasados nos pressupostos de Sternberg (1986). Nesse sentido, nas investigações de modelos conduzidas neste estudo, foram testadas as duas possibilidades. Os itens apresentaram cargas fatoriais adequadas nos dois modelos, bem como as estimativas de precisão. No entanto, ao observar os índices de ajuste, o modelo unifatorial apresentou ajustamento insatisfatório. Nesse sentido, a análise fatorial confirmatória com os três fatores possibilitou melhores índices de ajuste dos dados ao modelo. Assim, foi replicado matematicamente os pressupostos de Sternberg, corroborando os estudos Sternberg (1997), Gouveia et al. (2009) e de Andrade et. al (2013), e a divergir dos estudos com a ETAS no Brasil (Cassepp-Borges \& Pasquali, 2012, 2014; Cassepp-Borges \& Teodoro, 2007; Hernandez, 1999).

No entanto, a partir da análise dos resultados, foi possível identificar uma alta correlação entre os fatores, também encontrado na pesquisa de construção da Triangular Scale of Love
(Sternberg, 1997). Assim, os pesquisadores proponentes deste estudo investigaram a possibilidade de uma estrutura fatorial bi-factor, ou se seria mais coerente um modelo de segundaordem. Ainda que o modelo bi-factor, dentre os modelos testados, tenha apresentado melhor ajuste, verificou-se que poucos itens carregaram nos fatores específicos, e com cargas fatoriais no fator geral muito semelhantes ao modelo unifatorial. Conforme Reise, Morizot e Hays (2007), este dado sugeriria a solução unidimensional da escala. No entanto, conforme observado na primeira solução fatorial, todos os índices de ajuste indicaram o modelo unidimensional como inaceitável aos dados (Marôco, 2014).

Cabe destacar que, no modelo bi-factor, o fator especificado como paixão foi o que mais explicou a variância dos itens para além do fator geral de amor. Ao analisar o conteúdo dos quatro itens ("Tenho muito desejo pelo meu/minha parceiro(a)"; Sou muito satisfeito(a) sexualmente com meu/minha parceiro(a)"; "Sinto muita atração física pelo meu/minha parceiro(a)"); "Tenho vontade de ter relações sexuais com meu/minha parceiro(a) várias vezes ao dia"), é possível observar que todos esses itens referem-se à questões relacionadas ao desejo sexual e à atração física. Já os itens com conteúdos relacionados ao romance e idealização ("Quando estou apaixonado(a), fico empolgado(a)", "Quando assisto cenas de um filme romântico, penso em meu/minha parceiro(a)", "Na relação com meu/minha parceiro(a), existe algo mágico") foram explicados somente pelo fator geral - Amor. Assim, mediante análise dos dados, o desejo sexual seria independente do amor, e até mesmo da paixão, diferenciando uma dimensão relacionada à sensação romântica e outra à atração física. Desse modo, enquanto que na teoria triangular do amor (Sternberg, 1986) a paixão integraria à atração física, o desejo sexual, o romance e à satisfação por estar envolvido em um relacionamento amoroso, os dados sugerem que a paixão seria composta por dois fatores ortogonais, um relacionado ao romance, e outro ao desejo sexual, indicando a multidimensionalidade desse fator. 
Quadro 4. Análise fatorial confirmatória bi-factor

\begin{tabular}{|c|c|c|c|c|c|}
\hline Iten & & Amor & Intimidade & Paixão & Decisão \\
\hline 1 & Tenho um forte compromisso com meu/minha parceiro(a) & .75 & & & \\
\hline 2 & Percebo quando meu/minha parceiro(a) está chateado(a) & .56 & .42 & & \\
\hline 3 & Tenho muito desejo pelo meu/minha parceiro(a) & .58 & & .51 & \\
\hline 4 & Quando sei que irei magoar meu/minha parceiro(a), tenho cuidado para falar o que penso & .34 & & & \\
\hline 5 & $\begin{array}{l}\text { Abriria mão de ascensão profissional, se isso interferisse positivamente em minha relação } \\
\text { com meu/minha parceiro(a) }\end{array}$ & .46 & & & .73 \\
\hline 6 & Sou muito satisfeito(a) sexualmente com meu/minha parceiro(a) & .57 & & .56 & \\
\hline 7 & Valorizo muito a opinião de meu/minha parceiro(a) & .69 & & & \\
\hline 8 & Sinto muita atração física pelo meu/minha parceiro(a) & .63 & & .69 & \\
\hline 9 & Acredito no apoio de meu/minha parceiro(a) em relação a mim & .78 & & & \\
\hline 10 & Sou fiel ao meu/minha parceiro(a) & .72 & & & -.16 \\
\hline 11 & Me arrumo pensando em chamar a atenção do meu/minha parceiro(a) & .49 & & .15 & \\
\hline 12 & Deixaria de fazer um projeto pessoal para agradar meu/minha parceiro(a) & .44 & & & .65 \\
\hline 13 & Tenho vontade de ter relações sexuais com meu/minha parceiro(a) várias vezes ao dia & .29 & & .46 & \\
\hline 14 & Quando estou apaixonado(a), fico empolgado(a) & .49 & & .18 & \\
\hline 15 & Meu/minha parceiro(a) sempre pergunta minha opinião sobre os assuntos de seu interesse & .57 & .18 & & \\
\hline 16 & Consigo perceber quando meu/minha parceiro(a) está com problemas & .46 & .66 & & \\
\hline 17 & Quando assisto cenas de um filme romântico, penso em meu/minha parceiro(a) & .62 & & .14 & \\
\hline 18 & Na relação com meu/minha parceiro(a), existe algo mágico & .65 & & .24 & \\
\hline 19 & Divido meus planos de vida com meu/minha parceiro(a) & .81 & & & \\
\hline 20 & Tenho certeza de meu amor pelo meu/minha parceiro(a) & .85 & & & .06 \\
\hline 21 & A relação com meu/minha parceiro(a) foi uma das melhores decisões da minha vida & .79 & & & .24 \\
\hline 22 & Espero admirar meu/minha parceiro(a) por toda vida & .86 & & & .15 \\
\hline 23 & Me esforço para manter meu relacionamento & .78 & & & \\
\hline 24 & Escolho não ter relações sexuais com outras pessoas & .65 & & & \\
\hline 25 & Compartilho com meu/minha parceiro(a) minhas intimidades & .80 & .14 & & \\
\hline 26 & Gostaria de manter a relação com meu/minha parceiro(a) por muito tempo & .88 & & & \\
\hline 27 & Ajudo meu/minha parceiro(a) a cuidar de sua saúde & .70 & .26 & & \\
\hline 28 & Em momentos de necessidade meu/minha parceiro(a) pode contar com meu apoio & .77 & .18 & & \\
\hline 29 & Peço a opinião do meu/minha parceiro(a) quando sinto necessidade & .77 & .19 & & \\
\hline
\end{tabular}

No que diz respeito à relação entre esses dois comportamentos em relações amorosas, vale ressaltar que as pessoas podem ter relacionamentos românticos que não são sexuais e relacionamentos sexuais que não são românticos, e existem ainda relacionamentos que possuem comportamentos românticos e sexuais. Também é possível observar uma diminuição do comportamento sexual de pessoas em relações amorosas de longa duração com o passar dos anos, ainda que estejam presentes as outras dimensões, como afeto, intimidade, romance e a manutenção da relação (Busby, Willoughby, \& McDonald, 2019).

Em seguida, o modelo hierárquico de segunda-ordem foi testado. Os índices de ajuste desse modelo aos dados foram considerados bons (Marôco, 2014) e os coeficientes estruturais do fator geral em direção aos específicos foram significativos e elevados. Assim, os resultados sugerem o Amor como um construto de segundaordem, constituído pela Intimidade, Paixão e Decisão/Compromisso - principais dimensões do amor segundo a teoria de Sternberg (1986).

Ressalta-se que o modelo bi-factor apresentou melhores índices de ajuste que o de segundaordem, ainda que este também tenha apresentado boa adequação do modelo testado aos dados. Para interpretar tal dado, no modelo bi-factor, os fatores ortogonais acrescentam variância explicada para além do fator geral modelado, aumentando o número de fontes que explicam os itens, o que tende a melhorar os índices de ajuste, exigindo consistência teórica para interpretação dos dados. Já no modelo de segunda-ordem, o fator geral explica os itens por meio dos fatores de primeira-ordem. Assim, enquanto que no primeiro modelo não haveria uma relação direta entre o fator geral e os ortogonais, no modelo de segundaordem há uma relação direta e causal do fator de segunda-ordem em direção aos fatores de primeira (Schmid, 1957). Assim, justifica-se a escolha do modelo hierárquico de segunda-ordem devido aos bons índices de ajuste do modelo aos dados, e também teoricamente, uma vez que segundo a teoria triangular do amor que fundamentou a construção da E-AMOR, o amor seria um fator global que representa os comportamentos de intimidade, paixão e decisão/compromisso (Sternberg, 1986). No que diz respeito à utilização prática do instrumento, as evidências subsidiam o cálculo de um escore global de amor, por meio da mensuração dos fatores de intimidade, paixão e decisão/compromisso. 
Os resultados desta pesquisa proporcionam melhor compreensão do amor romântico, corroborando a estrutura multidimensional do construto, e não uma perspectiva unidimensional, o que poderia gerar vieses de mensuração, bem como compreensões equivocadas acerca de como o construto estabelece relações com variáveis externas. Além da estrutura interna, ter instrumentos com boas estimativas de precisão e de validade é de extrema importância para se ter maior confiabilidade dos resultados. Desse modo, este estudo reuniu evidências de estrutura interna iniciais para a E-AMOR, bem como evidenciou boas estimativas de precisão dos escores da escala. A identificação de um modelo de segundaordem auxiliará pesquisadores tanto Brasil, como de outros países a uma melhor compreensão do fenômeno. No que diz respeito aos terapeutas que atuam na área da conjugalidade, os resultados gerados a partir da utilização da escala os auxiliarão no desenvolvimento de intervenções mais assertivas no campo das relações românticas, uma vez que as evidências suportam que intimidade, paixão e decisão/compromisso como componentes do amor.

Em estudos futuros, recomenda-se a investigação de um modelo bi-factor sem os itens de paixão relacionados aos comportamentos sexuais, com o objetivo de identificar se a remoção dos itens melhoraria os índices de ajuste da estrutura fatorial. Além disso, sugere-se que sejam realizados estudos longitudinais com casais, que testem a estabilidade dos escores do modelo de segunda-ordem, bem como a realização de estudos transculturais para avaliar se diferenças culturais influenciam na estrutura do modelo fatorial do amor. Indicam-se algumas limitações deste estudo para que possam ser sanadas, como a representatividade da amostra, que se concentrou majoritariamente em: sexo feminino, indivíduos que estavam namorando, um único estado do Brasil e por estudantes universitários. Ademais, reforça-se a importância de estudos explorem as associações do amor com variáveis ainda pouco exploradas na literatura, como forças pessoais e também pesquisas que reúnam evidências de validade adicionais para E-AMOR, que investiguem relações com constructos já estabelecidos na literatura, como bem-estar (Hudson, Lucas, \& Donnellan, 2019), indicadores de saúde mental (Mirsu-Paun \& Oliver, 2017) e satisfação conjugal. Isso permitirá um aprofundamento da compreensão da potência desses sentimentos na vivência da conjugalidade. Destaca-se também a importância verificar as correlações da E-AMOR com alguma das versões existentes da escala de Sternberg em língua portuguesa, com o objetivo de investigar a validade concorrente da escala, uma vez que se propõem a mensuração do amor romântico.

\section{Referências}

Acker, M., \& Davis, M. H. (1992). Intimacy, passion and commitment in adult romantic relationships: A test of the triangular theory of love. Journal of Social and Personal Relationships, 9(1), 21-50. https://doi.org/10.1177/0265407592091002

Andrade, A. L., Garcia, A., \& Cassepp-Borges. (2013). Evidências de validade da Escala Triangular do Amor de Sternberg - Reduzida (ETAS-R). Psico-USF, 18(3), 501-510. https://doi.org/10.1590/S141382712013000300016

Aron, A., \& Westbay, L. (1996). Dimensions of the prototype of love. Journal of Personality and Social Psychology, 70(3), 535-51. https://doi.org/10.1037/0022-3514.70.3.535

Busby, D. M., Willoughby, B. J., \& McDonald, M. L. (2019). Is it the sex, the romance or the living together? The differential impact of past sexual, romantic, and cohabitation histories on current relationship functioning. Couple and Family Psychology: Research and Practice, 8(2), 90104. https://doi.org/10.1037/cfp0000117

Chojnacki, J. T., \& Walsh, W. B. (1990). Reliability and concurrent validity of the Sternberg Triangular Love Scale. Psychological Reports, 67(1), 219-224. https://doi.org/10.2466/pr0.1990.67.1.219

Carreño, M., \& Serrano, G. (1995). Análisis de instrumentos para la medida del amor. Revista de Psicología Social, 10(2), 131-148. https://doi.org/10.1174/021347495763810938

Cassepp-Borges, V., \& Pasquali, L. (2012). Estudo nacional dos atributos psicométricos 
da Escala Triangular do Amor de Sternberg. Paidéia, 22(51), 21-31.

https://doi.org/10.1590/s0103$863 \times 2012000100004$

Cassepp-Borges, V., \& Pasquali, L. (2014). A redução de itens como uma alternativa para a Escala Triangular do Amor. Psicologia, 28(2), 11-20. https://doi.org/10.17575/-rpsicol.v28i2.269

Cassepp-Borges, V., \& Teodoro, M. L. M. (2007). Propriedades psicométricas da versão brasileira da escala triangular do amor de Sternberg. Psicologia: Reflexão e Crítica, 20(3), 513-522.

https://doi.org/10.1590/s010279722007000300020

Damásio, B. F. (2012). Uso da análise fatorial exploratória em psicologia. Avaliação Psicológica, 11(2), 213-228. Recuperado de http://pepsic.bvsalud.org/pdf/avp/v11n2/v11n 2a07.pdf

Draganović, S., \& Hasanagic, A. (2015). Exploring the difference between Turkish and Bosnian students in Triangular Love scale. Epiphany, 7(2), 128-141. https://doi.org/10.21-533/epiphany.v7i2.108

Fehr, B., \& Russel, J. A. (1991). The concept of love viewed from a prototype perspective. Journal of Personality Social Psychology, (60), 425-438. Recuperado de https://pdfs.semanticscholar.org/7a5c/b3992e8 5630d46d95d6abc9c0a82846dfe60.pdf

Gouveia, V. V., Fonseca, P. N., Cavalcanti, J. P. N., Diniz, P. K. C., \& Dória, L. C. (2009). Versão abreviada da Escala Triangular do Amor: Evidências de validade fatorial e consistência interna. Estudos de Psicologia, 14(1), 31-39.

https://doi.org/10.1590/S1413-

294X2009000100005

Haack, K. R., \& Falcke, D. (2014). Love and marital quality in romantic relationships mediated and non-mediated by internet. Paidéia, 24(57), 105-113. https://doi.org/10.15-90/198243272457201413

Hendrick, C., \& Hendrick, S. S. (1989). Research on love: Does it measure up? Journal of Personality and Social Psychology, 56(5), 784-94. https://doi.org/10.1037/0022-3514.56.5.784

Hernandez, J. A. E. (1999). Validação da estrutura da Escala Triangular do Amor: Análise fatorial confirmatória. Aletheia, 9(1), 15-25. Recuperado de http://www.scielo.br/pdf/pusf/v18n3/a16v18n 3.pdf

Hernandez, J. A. E., Plácido, M. G., Araujo, A. L., Neves, V. C., \& Azevedo, C. A. C. B. (2014). A psicologia do amor: Vinte anos de estudos científicos nacionais. Psicologia Argumento, 32(79), 131-139.

http://dx.doi.org/10.7213/psicol..argum.32.s02 .AO12

Hudson, N. W., Lucas, R. E., \& Donnellan, M. B. (2019). The highs and lows of love: Romantic relationship quality moderates whether spending time with one's partner predicts gains or losses in well-being. Personality and Social Psychology Bulletin, 46(4), 1-18. https://doi.org/10.1177/0146167219867960

International Test Commission-ITC (2017). The ITC guidelines for translating and adapting tests (Second edition). Recuperado de https://www.intestcom.org/files/guideline_test _adaptation_2ed.pdf

Lorenzo-Seva, U., \& Ferrando, P. J. (2013). FACTOR 9.2: A comprehensive program for fitting exploratory and semiconfirmatory factor analysis and IRT models. Applied Psychological Measurement, 37(6), 497-498. https://doi.org/10.1177/014662-1613487794

Lucas, H., Csikszentmihalyi, M., \& Nakamura, J. (2019). Beyondpersonal love - Experiencing love beyond the person. The Journal of Positive Psychology, 1-10. https://doi.org/10.1080/17439760.2019.1579354

Marôco, J. (2010). Análise de equações estruturais. Lisboa, Portugal: ReportNunmber.

Marôco, J. (2014). Análise de equações estruturais: Fundamentos teóricos, software \& aplicações. 2nd Edn. Pêro Pinheiro: ReportNumber.

Mirsu-Paun, A., \& Oliver, J. A. (2017). How much does love really hurt? A meta-analysis of the association between romantic relationship quality, breakups and mental health outcomes in adolescents and young 
adults. Journal of Relationships Research, 8, 1-12. https://doi.org/10.1017/jrr.2017.6

Peterson, C., \& Seligman, M. E. P. (2004). Character strengths and virtues: A handbook and classification. Washington, DC, US: Oxford University Press.

Rubin, Z. (1970). Measurement of romantic love. Journal of Personality and Social Psychology, 16, 265-273. https://doi.org/10.1037/h0029841

Schmid, J. (1957). The comparability of the bifactor and second-order factor patterns. The Journal of Experimental Education, 25(3), 249253.

https://doi.org/10.1080/00220973.1957.11010 575

Sternberg, R. J. (1986). A triangular theory of love. Psychological Review, 93(2), 119-135. https://doi.org/10.1037/0033-295X.93.2.119

Sternberg, R. J. (1989). El triángulo del amor: Intimidad, amor y compromiso. Barcelona, ES: Ed. Paidós.

Sternberg, R. J. (1997). Construct validation of a Triangular Love Scale. European Journal of Social Psychology, 27(3), 313-335. https://doi.org/10.1002/(SICI)10990992(1997 05)27:3<313::AID-EJSP824>3.0.CO;2-4

Sumter, S. R., Valkenburg, P. M., \& Peter, J. (2013). Perceptions of love across the lifespan: Differences in passion, intimacy, and commitment. International Journal of Behavioral Development, 37(5), 417-427. https://doi.org/10.1177/016502541-3492486

Whitley, B. E. (1993). Reliability and aspects of the construct validity of Sternberg's Triangular Love Scale. Journal of Social and Personal Relationships, 10(3), 475-480. https://doi.org/10.1177/0265407593103013 